\title{
Confirmatory Factor Analysis of Organizational Citizenship Behavior of Generation Y Teachers in Thailand
}

\author{
Nuchchamon Pramepluem ${ }^{1}$, Pinkanok Wongpinpech ${ }^{2}$, Manop Chunin ${ }^{2}$ \\ ${ }^{1}$ Faculty of Education, Ramkhamhaeng University,Bangkok,Thailand \\ ${ }^{2}$ Faculty of Applied Arts, King Mongkut's University of Technology North Bangkok Bangkok,Thailand
}

\begin{abstract}
The objectives of this research were to examine the structural characteristics of organizational citizenship behavior of Generation $Y$ teachers in Thailand. The participants were 150 teachers from 12 schools under the Secondary Educational Service Area Office 9 in Thailand. The research tools were five rating scales questionnaires. The data was analyzed by a confirmatory factor analysis. The results showed that altruism, courtesy, sportsmanship, conscientiousness, civic virtue, and self-development feedback were confirmed as six facets of generation $Y$ teachers' organizational citizenship behavior.
\end{abstract}

Keywords - confirmatory factor analysis, organizational citizenship behavior, Generation $\mathbf{Y}$, teacher.

\section{Introduction}

In order to sustainably develop a country, strengthening the country's existing capital assets needs much attention in order that these capital assets should suffice for national development process steering, especially human development or human capital development.

DOI: $10.18421 /$ SAR34-02

https://doi.org/10.18421/SAR34-02

Corresponding author: Pinkanok Wongpinpech,

Faculty of Applied Arts, King Mongkut's University of Technology North Bangkok,1518, Wongsawang, Bangsue, Bangkok 10800, Thailand.

Email: pinkanok.w@arts.kmutnb.ac.th

Received: 06 August 2020.

Revised: 05 December 2020.

Accepted: 12 December 2020.

Published: 30 December 2020.

(c) BY-NC-ND (C) 2020 Nuchchamon Pramepluem, Pinkanok Wongpinpech \& Manop Chunin; published by UIKTEN. This work is licensed under the Creative Commons Attribution-NonCommercial-NoDerivs 3.0 License.

The article is published with Open Access at www.sarjournal.com
Human capital has to be adequately prepared for the change in $21^{\text {st }}$ century. Also, creating environmental factors which are conducive to human quality development in terms of social structure encourages people to become immune to the future change [1]. Consequently, the government has placed great importance on population development. It has quickly developed people regarding all dimensions, including educational personnel considering them important and essential for social and national steering. Their efficiency is required to be promoted and reinforced so that they can always keep themselves up to date with the change and have essential career knowledge and skills.

Organizational citizenship behavior is a personnel's willingness to take additional responsibilities. It is a work behavior that supports and is essential for overall organizational operations which lead to success. Moreover, it greatly develops organizational efficiency and effectiveness. It is considered as a helpful behavior for organization development [2] [3]. Therefore, it cannot be denied that organizational citizenship behavior is highly essential for organizations. However, in school context where the roles of schools in education affect future human resources and are highly important for developing countries in which teachers with high organizational citizenship behavior are needed, it is more sensitive and important [4]. Furthermore, one of the teachers' responsibilities is to improve students' learning by teaching. When considered the complex nature of learning, teachers cannot only perform official duties [5]. If a teacher has organizational citizenship behavior, it will positively affect students, colleagues, schools, and community. Especially, it is one of the important factors that helps encourage and improve knowledge, goodness, well-being, morality and ethics, discipline, and public consciousness.

Age diversity is one of the major dynamic factors affecting organizational operations steering. An organization with personnel of different generations creates creative work environment which influences organizational efficiency and is useful for the 
organization. Therefore, to create and choose age diversity management techniques and strategies appeal to most leading organizations. Understanding age differences helps an organization recruit, improve, and retain personnel with skills and abilities of each generation in perpetuity [6].

In Thailand, there are over 18 million Generation Y, constituting 27 percent of the total population. However, in terms of the labor force, the percentage of Generation Y population is 42 percent. They are considered as the important human resources in steering country. Therefore, examining Generation Y's behaviors is an intriguing thing to do, since their characteristics and thoughts are different from Baby Boomers and Generation X's [7]. According to the employee structure, most teachers under the Secondary Educational Service are also Generation $Y$. The number of Generation $Y$ teachers under the Secondary Educational Service Area Office 9 is the seventh largest of all Secondary Educational Service [8]. As Generation $\mathrm{Y}$ teachers are responsible for students at important ages who start to face social complexity, it is absolutely necessary for the teachers to have a positive attitude at work; a willingness to enhance their career knowledge, skills, and abilities to be capable of teaching; and other things that are mainly helpful for the students and schools. Moreover, instead of only performing official duties regarding working hours, the teachers should also be willing to help students, colleagues, and schools, using any necessary methods.

According to the aforementioned significances, the researchers aimed at examining a confirmatory factor of organizational citizenship behavior of Generation $\mathrm{Y}$ teachers. The results of this research would help understand appropriate factors used for improving organizational citizenship behaviors of Generation Y teachers under the Secondary Educational Service Area Office 9.

\section{Objectives}

This research is aimed at examining the structural characteristics of organizational citizenship behavior of generation $\mathrm{Y}$ teachers under the Secondary Educational Service Area Office 9 in Thailand.

\section{Literature Review}

Organ [9] reported that organizational citizenship behavior was a personal discretionary behavior regardless of an organization's reward system, showing support on effective organizational operations. When considered components of organizational citizenship behavior, Organ [9] divided organizational citizenship behavior into 5 components: 1) altruism or a personnel's willingness to promptly help other co-workers with resolving any problems occurred at work, counsel new personnel, and provide necessary equipment or resources, 2) courtesy or a personnel's willingness to help other co-workers with preventing problems, be considerate to other co-workers before taking any action, respect other co-workers' rights, and share organizational resources, 3) sportsmanship or a personnel's willingness to endure difficulties, disappointment, stress, and inconvenience that may occur during work time without complaining or resenting, 4) conscientiousness or a personnel's willingness to adhere to an organization's rules and policies, take care of and maintain organizational assets, and spend time in an organization and use organizational resources worthily, and 5) civic virtue or a personnel's willingness to take responsibilities for and participate in organizational processes by expressing opinions, following the news about an organization, and improving an organization in all aspects. Furthermore, when the researchers reviewed components of organizational citizenship behavior among teachers, it was found that numerous academicians focused on the topic. For instance, Skarlicki and Latham [10] studied organizational citizenship behavior in universities. The supporting information on components of organizational citizenship behavior was that it consisted of 2 components: organizational and interpersonal component. Oplatka [11] conducted qualitative research on components of organizational citizenship behavior of teachers. It appeared that there were 4 components of organizational citizenship behavior of teachers: students, classrooms, colleagues, and schools. Concepts of these components were based on a study of the following points: 1) students and colleagues supporting behavior, 2) the initiative in changing and innovative teaching, 3) strong organization emphasizing, and 4) absolute loyalty for teaching profession. Talebloo et al. [12] investigated dimensions of organizational citizenship behavior based on primary state school Malaysian teachers' perceptions and examined components of organizational citizenship behavior based on the concepts of 5 components of Organ which were altruism, courtesy, sportsmanship, conscientiousness, and civic virtue. Moreover, Shaheen, Gupta, and Kumar [13] conducted qualitative research on components of organizational citizenship behavior of teachers and revealed that it consisted of 3 components: Organizational Citizenship BehaviorIndividual (OCB-Individual), Organizational Citizenship Behavior- Organization (OCBOrganization), and Organizational Citizenship Behavior- Prosocial (OCB-Prosocial).

The aforementioned concepts and theories can be summarized as follows: In this research, 
organizational citizenship behavior was a behavior of a dedicated teacher who had enhanced themselves in terms of psychology and social, and performed duties to the utmost although those duties were beyond their responsibilities, to encourage and support community, students, colleagues, and schools so that they achieved their explicit goals. It could be categorized into 6 components which were altruism, conscientiousness, sportsmanship, courtesy, civic virtue, and developing oneself. For research hypothesis, it was that the measurement model of organizational citizenship behavior of Generation Y teachers fit for the empirical data.

\section{Research Methodology}

\subsection{Population and Sample}

Population were 709 teachers from 61 schools under the Secondary Educational Service Area Office 9 in Thailand. The samples were 150 teachers from 29 schools under the Secondary Educational Service Area Office 9 in Thailand. This sample size was based on stratified random sampling.

\subsection{Research Instrument}

The organizational citizenship behavior of Generation $Y$ teachers measurement based on concepts, theories, and related documents and research was divided into 6 components. There were 33 questions. Each question displayed 5-rating-scale answers from strongly disagree to strongly agree, and all questions were positive. Reliability of the measurement was at .933 .

\subsection{Data Analysis}

The researchers analyzed Pearson's correlation of observed variables and made a confirmatory factor analysis (CFA) from correlation matrix.

\section{Research Results}

The results of a confirmatory factor analysis model of organizational citizenship behavior revealed that the measurement model of organizational citizenship behavior of Generation $\mathrm{Y}$ teachers fit for the empirical data. The result of examination the model fit indexes were that a chi-square statistic was 731.437 , a degree of freedom was 482, a statistical significance was 0.00 (a p-value can be less than $0.05)$, a root mean square error of approximation (RMSEA) was 0.059 (it should be less than 0.08), comparative fit index (CFI) was 0.977 (it should be higher than 0.92), relative fit index (RFI) was 0.930 (it should be higher than 0.92), and standardized root mean square residual (SRMR) was 0.074 (it should be less than 0.09).

When considered each observed variable, it was found that standardized factor loadings of 33 observed variables were between 0.436 and 0.886 . All factor loadings were statistically significant at 0.01 level. The variable with the highest standardized factor loading was ocb27 "You always follow the news about your school and school movement". The standardized factor loading was at 0.886 , and it was 74.9 percent in joint variation with organizational citizenship behavior, followed by ocb28 "You pay attention to school notifications" with a standardized factor loading of 0.886 and ocb15 "Although you face problems during work, you will try your best to resolve them" with a standardized factor loading of 0.818 . Respectively, these variables were 74.9 and 66.8 percent in joint variation with organizational citizenship behavior.

When considered the second order confirmatory factor analysis, standardized factor loadings of latent variables, altruism, conscientiousness, sportsmanship, courtesy, civic virtue, and developing oneself, were at 0.721 to 0.947 . Courtesy had the highest factor loading, followed by developing oneself and sportsmanship. Respectively, these latent variables were $89.7,72.4$, and 67.8 percent in joint variation with organizational citizenship behavior. The detail data analysis result was shown in Table 1 and Figure 1. 
SAR Journal. Volume 3, Issue 4, Pages 154-159, ISSN 2619-9955, DOI: 10.18421/SAR34-02, December 2020.

Table 1. Result of Confirmatory Factor Analysis

\begin{tabular}{|c|c|c|c|c|c|c|}
\hline \multirow{2}{*}{$\begin{array}{l}\text { Confirmatory } \\
\text { Factor Analysis }\end{array}$} & \multirow{2}{*}{$\begin{array}{l}\text { Manifest } \\
\text { Variables }\end{array}$} & \multicolumn{4}{|c|}{ Factor Loading } & \multirow{2}{*}{$\mathrm{R}^{2}$} \\
\hline & & $\mathrm{B}$ & (Beta) & SE & $\mathrm{t}$ & \\
\hline \multirow{6}{*}{ Second Order } & Alt & 0.780 & & 0.108 & $7.213^{* *}$ & 0.608 \\
\hline & Con & 0.739 & & 0.190 & $3.895 * *$ & 0.547 \\
\hline & Spo & 0.824 & & 0.069 & $11.974 * *$ & 0.678 \\
\hline & $\mathrm{Cou}$ & 0.947 & & 0.078 & $12.212^{* *}$ & 0.897 \\
\hline & Civ & 0.721 & & 0.120 & $6.007 * *$ & 0.520 \\
\hline & Ini & 0.851 & & 0.104 & $8.220 * *$ & 0.724 \\
\hline \multirow{33}{*}{$\begin{array}{l}\text { First } \\
\text { Order }\end{array}$} & ocb1 & 0.483 & $(0.614)$ & & & 0.377 \\
\hline & ocb2 & 0.556 & $(0.787)$ & 0.064 & $8.675^{* *}$ & 0.620 \\
\hline & ocb3 & 0.336 & $(0.570)$ & 0.063 & $5.328 * *$ & 0.325 \\
\hline & ocb4 & 0.297 & $(0.543)$ & 0.052 & $5.679 * *$ & 0.295 \\
\hline & ocb5 & 0.445 & $(0.701)$ & 0.053 & $8.362 * *$ & 0.491 \\
\hline & ocb6 & 0.188 & $(0.608)$ & & & 0.370 \\
\hline & ocb7 & 0.255 & $(0.616)$ & 0.044 & $5.831 * *$ & 0.830 \\
\hline & ocb8 & 0.190 & $(0.436)$ & 0.057 & $3.306^{* *}$ & 0.190 \\
\hline & ocb9 & 0.216 & $(0.577)$ & 0.055 & $3.977 * *$ & 0.333 \\
\hline & ocb10 & 0.284 & $(0.774)$ & 0.064 & $4.417 * *$ & 0.599 \\
\hline & ocb11 & 0.262 & $(0.737)$ & 0.057 & $4.579 * *$ & 0.543 \\
\hline & ocb12 & 0.348 & $(0.657)$ & 0.071 & $4.907 * *$ & 0.431 \\
\hline & ocb13 & 0.307 & $(0.712)$ & 0.060 & $5.097 * *$ & 0.507 \\
\hline & ocb14 & 0.259 & $(0.714)$ & 0.060 & $4.319 * *$ & 0.510 \\
\hline & ocb15 & 0.416 & $(0.818)$ & & & 0.668 \\
\hline & ocb16 & 0.431 & $(0.755)$ & 0.035 & $12.413^{* *}$ & 0.570 \\
\hline & ocb17 & 0.468 & $(0.743)$ & 0.046 & $10.207 * *$ & 0.552 \\
\hline & ocb18 & 0.375 & $(0.759)$ & 0.028 & $13.409 * *$ & 0.576 \\
\hline & ocb19 & 0.453 & $(0.808)$ & 0.027 & $16.655^{* *}$ & 0.653 \\
\hline & ocb20 & 0.459 & $(0.815)$ & & & 0.665 \\
\hline & ocb21 & 0.552 & $(0.773)$ & 0.048 & $11.405^{* *}$ & 0.597 \\
\hline & ocb22 & 0.531 & $(0.775)$ & 0.045 & $11.801 * *$ & 0.601 \\
\hline & ocb23 & 0.283 & $(0.604)$ & 0.029 & $9.683^{* *}$ & 0.365 \\
\hline & ocb24 & 0.415 & $(0.723)$ & 0.043 & $9.559 * *$ & 0.523 \\
\hline & ocb25 & 0.387 & $(0.646)$ & 0.044 & $8.744 * *$ & 0.418 \\
\hline & ocb26 & 0.407 & $(0.600)$ & & & 0.360 \\
\hline & ocb27 & 0.423 & $(0.886)$ & 0.053 & $8.002 * *$ & 0.786 \\
\hline & ocb28 & 0.441 & $(0.866)$ & 0.052 & $8.449 * *$ & 0.749 \\
\hline & ocb29 & 0.438 & $(0.655)$ & & & 0.429 \\
\hline & ocb30 & 0.436 & $(0.725)$ & 0.049 & $8.810^{* *}$ & 0.525 \\
\hline & ocb31 & 0.404 & $(0.733)$ & 0.047 & $8.600 * *$ & 0.538 \\
\hline & ocb32 & 0.353 & $(0.691)$ & 0.047 & $7.599 * *$ & 0.477 \\
\hline & ocb33 & 0.485 & $(0.695)$ & 0.058 & $8.414 * *$ & 0.483 \\
\hline
\end{tabular}

** a significance level of .01 , Ocb1-33=1-33 items of Organizational Citizenship Behavior, Alt $=$ Altruism, Con $=$ Conscientiousness, $\mathrm{Spo}=$ Sportsmanship, Cou $=$ Courtesy, $\mathrm{Civ}=$ Civic virtue, Ini $=$ Individual Initiative 


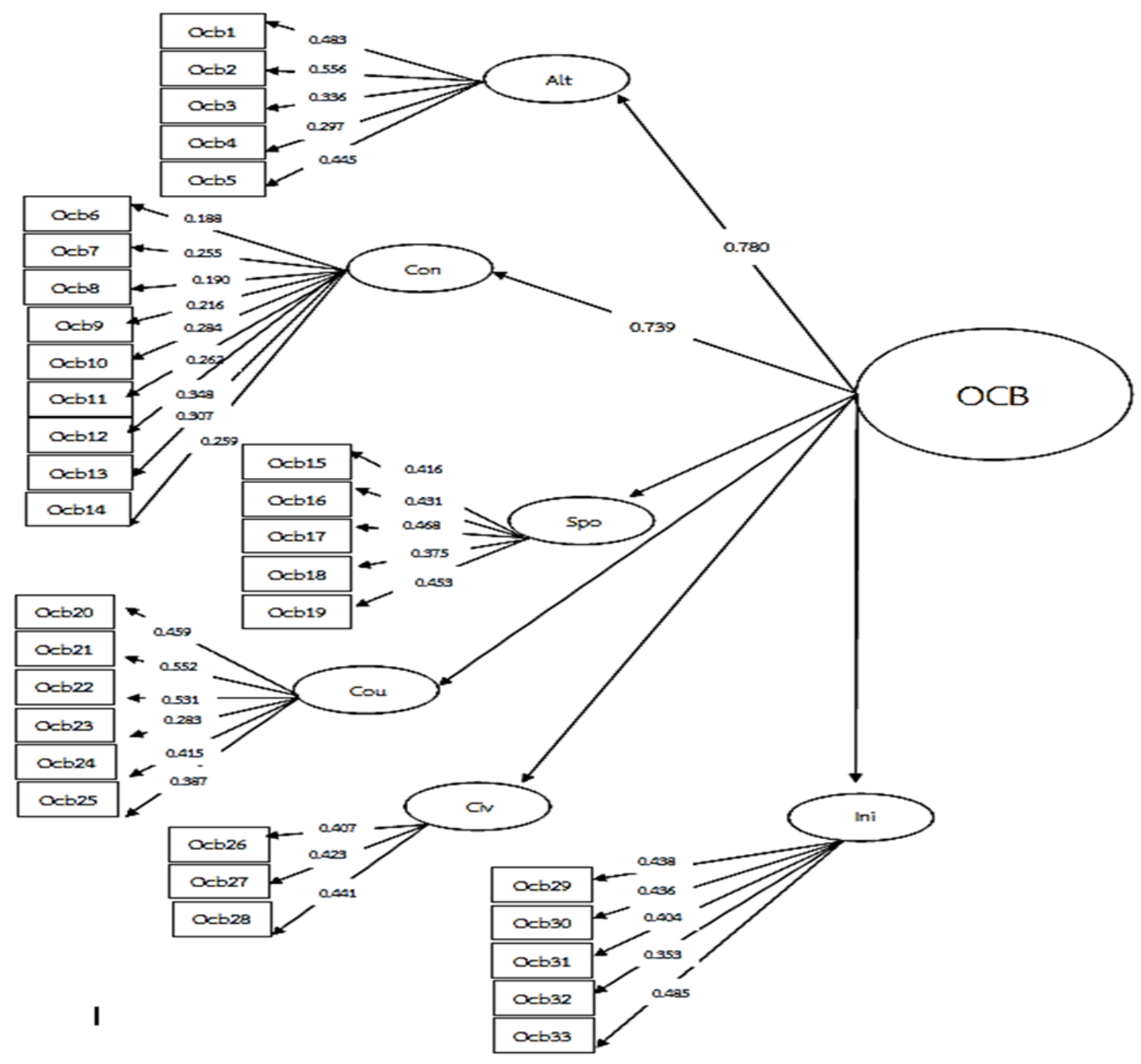

Figure 1. A Confirmatory Factor Analysis Model of Organizational Citizenship Behavior of Generation $Y$ Teachers

\section{Conclusion and Discussion}

After examining construct validity of organizational citizenship behavior of Generation Y teachers' measurement model with the empirical data, it showed that the results were in accordance with the hypothesis. The results of the first order confirmatory factor analysis showed that organizational citizenship behavior of Generation Y teachers' measurement model was congruent with the empirical data. Organizational citizenship behavior of Generation Y teachers consisted of 6 main components. All factor loadings were positive and in between 0.436 and 0.886 with statistical significance at 0.01 level. Nevertheless, organizational citizenship behavior of Generation Y teachers had 33 observed variables. All observed variables had a correlation with the 6 main components. All factor loadings were positive and in between 0.721 and 0.947 . Therefore, this model had construct validity. When considered priority of components, 1) courtesy has the highest priority, followed by 2) developing oneself and 3) sportsmanship. Factor loadings were
0.947, 0.851, and 0.824 respectively. Correspondingly, Organ [9] categorized organizational citizenship behavior into 5 components which were altruism, courtesy, sportsmanship, conscientiousness, and civic virtue. The concepts of developing oneself of Podsakoff et al. [14] and George and Jones [15] also conformed to Organ's statement [9].

The results of a confirmatory factor analysis of organizational citizenship behavior revealed that related departments should create activities to develop organizational citizenship behavior of Generation $\mathrm{Y}$ teachers regarding each component. Moreover, organizational citizenship behavior of Generation Y teachers' measurement could be used for measuring organizational citizenship behavior of teachers under other Secondary Educational Service as the measurement has construct validity and reliability that are eligible for criteria. In order that any researchers wish to use the measurement with other sample groups, some specific questions in the survey might need to be adjusted. 


\section{References}

[1]. Office of The Permanent Secretary Ministry of Education. (2012). Government Action Plan (2013 2016). Bangkok: Ministry of Education.

[2]. Pepe, A., Addimando, L., \& Veronese, G. (2017). Measuring teacher job satisfaction: assessing invariance in the teacher job satisfaction scale (TJSS) across six countries. Europe's journal of psychology, 13(3), 396.

[3]. Hemakumara, M. G. G., Khatibi, A. A., \& Johar, M. G. (2018). Job satisfaction and organizational citizenship behavior among the administrative staff of state universities in Sri Lanka. International Journal of Management Sciences and Business Research, 7(8), 40-44.

[4]. Jenaabadi, H., Okati, E., \& Sarhadi, A. (2013). Organizational Citizenship Behavior, Job Satisfaction and Commitment to School: Is There Any Significant Difference between Male and Female Teachers?. World Journal of Education, 3(3), 75-81.

[5]. Oplatka, I. (2006). Going beyond role expectations: Toward an understanding of the determinants and components of teacher organizational citizenship behavior. Educational administration quarterly, 42(3), 385-423.

[6]. Jones, J. M., Dovidio, J. F., \& Vietze, D. L. (2013). The psychology of diversity: Beyond prejudice and racism. John Wiley \& Sons.

[7]. Bhubate, S. \& Niphon, D.. (2015). Lifestyle, Way of Life and Generation Y's concept of having a child.
[8]. Bureau of Personnel Administration Development and Legal Affairs. (2015). Database of Manpower divided by educational area. Bangkok: Ministry of Education.

[9]. Organ, D. W. (1990). The motivational basis of organizational citizenship behavior. Research in organizational behavior, 12(1), 43-72.

[10]. Skarlicki, D. P., \& Latham, G. P. (1995). Organizational citizenship behaviour and performance in a university setting. Canadian Journal of Administrative Sciences/Revue Canadienne des Sciences de l'Administration, 12(3), 175-181.

[11]. Oplatka, I. (2009). Organizational citizenship behavior in teaching: The consequences for teachers, pupils, and the school. The International Journal of Educational Management, 23(5), 375-389.

[12]. Talebloo, B., Basri, R. B., Asmiran, S. B., \& Hassan, A. (2015). Teachers' perceptions on transformational leadership based on demographic differences. MiddleEast Journal of Scientific Research, 23(6), 11051113.

[13]. Shaheen, M., Gupta, R., \& Kumar, Y. L. N. (2016). Exploring Dimensions of Teachers' OCB from Stakeholder's Perspective: A Study in India. The Qualitative Report, 21(6), 1095.

[14]. Podsakoff, P. M., MacKenzie, S. B., Paine, J. B., \& Bachrach, D. G. (2000). Organizational citizenship behaviors: A critical review of the theoretical and empirical literature and suggestions for future research. Journal of management, 26(3), 513-563.

[15]. George, J. M., Jones, G. R., \& Sharbrough, W. C. (2005). Understanding and managing organizational behavior. Upper Saddle River, NJ: Pearson Prentice Hall. 